\title{
LC-MS/MS Analysis and Hepatoprotective Activity of Artichoke (Cynara scolymus L.) Leaves Extract against High Fat Diet-Induced Obesity in Rats
}

\author{
Maryem Ben Salem, ${ }^{1}$ Kamilia Ksouda, ${ }^{1}$ Raouia Dhouibi, ${ }^{1}$ Slim Charfi, ${ }^{2}$ \\ Mouna Turki, ${ }^{3}$ Serria Hammami, ${ }^{1}$ Fatma Ayedi, ${ }^{3}$ Zouheir Sahnoun, ${ }^{1}$ \\ Khaled Mounir Zeghal, ${ }^{1}$ and Hanen Affes ${ }^{1}{ }^{1}$ \\ ${ }^{1}$ Laboratory of Pharmacology, Faculty of Medicine, University of Sfax, Tunisia \\ ${ }^{2}$ Laboratory of Anatomopathology, CHU Habib Bourguiba, University of Sfax, Sfax, Tunisia \\ ${ }^{3}$ Biochemistry Laboratory, CHU Habib Bourguiba, University of Sfax, Tunisia \\ Correspondence should be addressed to Hanen Affes; affeshanen13@yahoo.fr
}

Received 15 December 2018; Revised 7 April 2019; Accepted 23 April 2019; Published 23 May 2019

Academic Editor: Paul M. Tulkens

Copyright (C) 2019 Maryem Ben Salem et al. This is an open access article distributed under the Creative Commons Attribution License, which permits unrestricted use, distribution, and reproduction in any medium, provided the original work is properly cited.

\begin{abstract}
Cynara scolymus L. (Artichoke) has been used for the treatment of metabolic disorders. The purpose of the present study was to investigate the hepatoprotective effect of Cynara scolymus leaves extract against a high fat diet (HFD) induced rats. This study investigated the most abundant phenolic compounds rich Cynara scolymus leaves extract and it is antihypercholesterolemic and antioxidative effects in vivo. The hypercaloric high fat diet (HFD) was treated with $200 \mathrm{mg} / \mathrm{kg}$ and $400 \mathrm{mg} / \mathrm{kg}$ of ethanol extract (EEA) from leaves of Cynara and atorvastatin (ATOR) $(10 \mathrm{mg} / \mathrm{kg} /$ day) during an 8 -week period. Lipid profile was measured and oxidative stress systematic in hepatic tissue was determined. Our data revealed that HFD-induced hepatic dysfunction manifested by significant abnormal levels of AST, ALT, ALP, LDH, and OCT was accompanied by increasing levels of oxidative stress biomarker (ROS, MDA, and AOPP) while decreasing in antioxidant status. Coadministration of EEA significantly reduced serum lipid profile and hepatic disorders which was confirmed to be histological by reducing the fatty liver deposition in hepatic lobule. These findings suggest that Cynara leaves exert antiobesity and antioxidant liver effects in HFD-induced obese rats.
\end{abstract}

\section{Introduction}

Nowadays, many researchers proved that obesity was a chronic metabolic disease. This explained the imbalance between the energy expenditure and intake, and it is caused seriously by increase of fat mass and lipid disposition in blood [1]. Kuboota et al. [2] and Holland et al. [3] reported that obesity is correlated with many metabolic diseases such as hypercholesterolemia, diabetes, and cardiovascular disease. According to Park et al. [4], obesity is the most consequence of liver damage, so we necessarily research therapeutic files such as herbs to advance the adequacy of the risk correlated with obesity [5, 6]. Among the medicinal plants identified from Mediterranean area (North Africa and southern Europe), there was Cynara scolymus (Asteraceae). According to Lattanzio et al. [7], this medicinal plant is cultivated almost around the world, because of its beneficial nutrition effects like cooking and medicinal properties. From traditional therapy, Cynara extract has been used as a drug in the treatment of several diseases effects of the biliary tract, digestive action, scurvy, and anemia and also has an antiartherosclerotic effect $[8,9]$. Bonomi [10] explained that Cynara leaves extracts have been reported by many studies that it can be used alone or in association with other medicinal plants, to prepare herbal teas or medicinal plant-based capsule, according to Bonomi. Among the constituents of Cynara extract was the active compounds (polyphenols), which exhibited the potential antioxidants properties [11]. Many researchers reported that the treatment with various phenolic compounds achieved controlling the levels of lipid profile in HFD-fed rats $[12,13]$. 
Yet, there is a great data available on in vivo research of Cynara leaves extract included liver complication. For that reason, we seriously plan our study to think of the greatest treatment with Cynara leaves extract on hepatic dysfunction and oxidative status on a model of HFD rats.

\section{Materials and Methods}

2.1. Preparation of C. scolymus Leaves Extract. Leaves around the stems of C. scolymus were obtained and cut into smaller pieces and then dried at room temperature under shade in order to obtain powder and to be subjected to extraction.

The protocol of extraction mentioned by 200 grams of powder leaves was extracted with different solvents and different polarities $(1 \mathrm{~L} \times 72 \mathrm{~h})$ : hexane, ethyl acetate, butanol, $75 \% \mathrm{v} / \mathrm{v}$ (ethanol $/ \mathrm{H}_{2} \mathrm{O}$ ), and water.

All extracts were filtered, evaporated, and removed pressure using a Rotovapor at $40^{\circ} \mathrm{C}$ and lyophilized by freezedryer (Alpha 1-2 LD plus Martin Christ ${ }^{\circledR}$ ) to determine the weight of each extract and then stored at $4^{\circ} \mathrm{C}$ until analysis.

2.2. Determination of Total Phenol Content. Total phenol content of Cynara leaves extracts was determined using the method of Folin Ciocalteu by Fawole et al. [14]. The mixture contained $1 \mathrm{~mL}$ of Folin Ciocalteu reagent, $10 \mathrm{ml}$ of $\mathrm{NaCO}_{3}$, and $1 \mathrm{~mL}$ of each extract. Then, the absorbance of each mixture was measured at $750 \mathrm{~nm}$ after $30 \mathrm{~min}$. The total phenol content was expressed in terms of Gallic acid equivalent ( $\mathrm{mg}$ of GAE/g of extract).

2.3. LC-MS/MS Analysis. The antioxidant compound rich EEA from leaves of Cynara was identified by LC-MS/MS analysis which composed an Agilent 1100 LC system (Agilent Technologies, Santa Clara, CA) containing degasser, binary pump, autosampler, and column heater. The column outlet was coupled to an Agilent MSD Ion Trap XCT mass spectrometer (Agilent Technologies, Santa Clara, CA) equipped with an ESI ion source.

The personal computer with Data Analysis software (Chemstations) evaluated data acquisition and mass spectrometric. For the chromatographic separation, we used a Zorbax $300 \mathrm{~A}^{\circ}$ Extend-C-18 Column (2.1 $150 \mathrm{~mm}$; Phenomenex UK, Macclesfield, UK). The column was mixed by $95 \%$ solvent $\mathrm{A}(0.1 \%$ formic acid in water) and $5 \%$ solvent $\mathrm{B}$ $(0.1 \%$ formic acid in acetonitrile) for $1 \mathrm{~min}$, followed by an 11 min step gradient (5\% B to $100 \%$ B); then it was kept for 4 min with $100 \% \mathrm{~B}$. In the end, the elution was completed with a linear gradient from $100 \%$ to $5 \%$ B for $2 \mathrm{~min}$. The flow rate was adjusted at $200 \mathrm{ml} / \mathrm{min}$ and the volume was injected at $5 \mathrm{ml}$. The following parameters were regulated during all MS experiments: the polarity was charged with positive ion, the capillary voltage was established to $3.5 \mathrm{kV}$, the drying temperature was fixed to $350^{\circ} \mathrm{C}$, the nebulizer pressure was maintained to $40 \mathrm{psi}$, and the drying gas flow was measured to $10 \mathrm{~L} / \mathrm{min}$. Moreover, the maximum accumulation time was fixed to $50 \mathrm{~ms}$, the scan speed was $26000 \mathrm{~m} / \mathrm{z} / \mathrm{s}$ (ultra scan mode) and the time of fragmentation was $30 \mathrm{~ms}$.

The phenolic compounds were identified using a combination of two analytic methods: high-performance liquid chromatography (HPLC) with diode array detection and liquid chromatography with atmospheric pressure chemical ionization mass spectrometry (ESI- LC/MS/MS) on the basis of their ultraviolet (UV) spectra, mass spectra.

The mass spectra results were compared with those of available authentic standards.

2.4. Determination of Lipase Activity In Vitro. According to Nikai et al. [15], pancreatic lipase activity was measured using 4- methylumbelliferyl oleate (4-MU oleate) as a substrate. The mixture containing $25 \mu \mathrm{L}$ of each extract dissolved in DMSO and $50 \mu \mathrm{L}$ of $0.1 \mathrm{mM} 4-\mathrm{MU}$ solution dissolved in a buffer (13 mM Tris- $\mathrm{HCl}, 150 \mathrm{mM} \mathrm{NaCl})$ and $1.3 \mathrm{mM} \mathrm{CaCl}_{2}$ ( $\mathrm{pH}$ 8.0) was mixed in the well of a microtiter plate and then $25 \mu \mathrm{L}$ of the lipase solution $(50 \mathrm{U} / \mathrm{mL})$ in the above buffer was added in order to start the enzyme reaction. After incubation at $25^{\circ} \mathrm{C}$ for $30 \mathrm{~min}, 0.1 \mathrm{~mL}$ of $0.1 \mathrm{M}$ sodium citrate ( $\mathrm{pH} 4.2$ ) was added to block the reaction. The amount of 4-methylumbelliferone released by lipase was measured with a fluorometric microplate reader (Fluoroskan Ascent C LabSystems, Inc.) at an excitation wavelength of $360 \mathrm{~nm}$ with a tolerance of $\pm 40 \mathrm{~nm}$ and an emission wavelength of $460 \mathrm{~nm}$ with a tolerance of $\pm 20 \mathrm{~nm}$.

Orlistat is used as a positive control. PI: percentage of lipase pancreatic activity inhibition.

$$
\mathrm{PI}=\frac{\text { Absorbance control }- \text { Absorbance test }}{\text { Absorbance control }} * 100
$$

2.5. Animals and Diet. Thirty Wistar female rats, weighing $180 \pm 2 \mathrm{~g}$, were collected from the Tunisian Pharmaceutical Industries (SIPHAT, Tunisia). The environmental conditions of animals were kept in a controlled room (60\% humidity, $25^{\circ} \mathrm{C}$, and 12-h light-dark cycle) in the laboratory of Animal Ecophysiology of Sfax City, Tunisia. All these animal studies have occurred in this study guided by the International Guidelines for Animal Care and were accredited by the Tunisian Ethics Committee of the University of Sfax (Sfax, Tunisia).

Before animal experimentation, all animal were kept to acclimate for one week and fed on a standard diet (corn, soy, and vitamins) supplied by the Company of Animals Nutrition, Sfax, Tunisia.

2.6. Experimental Design. The creation of the model of high fat diet (HFD) was composed of 79.9\% normal diet, $10 \%$ sheep fats, and $0.1 \%$ cholic acid. 30 Wistar rats were divided into 5 groups $(\mathrm{n}=6$ six $)$ :

Groups I: (C). Control rats fed on a standard diet.

Groups II: (HFD). Rats fed on the high fat diet, for 8 months.

Groups III: HFD + ATOR. Rates fed on HFD and treated with $10 \mathrm{mg} / \mathrm{kg} / \mathrm{bw}$ a commercial drug ATOR (atorvastatin) by gastric gavages route in a volume of $1 \mathrm{ml}$ during 2 months daily [16].

Groups IV: HFD+ EEA (200mg/kg/bw). Rats fed on HFD and treated with ethanol extract from leaves of Cynara scolymus at doses $200 \mathrm{mg} / \mathrm{kg} / \mathrm{bw}$ by gastric gavages route in a volume of $1 \mathrm{ml}$ during 2 months daily [17]. 
Groups VI: HFD+ EEA (400mg/kg/bw). Rats fed on HFD and treated with ethanol extract from leaves of Cynara scolymus at doses $400 \mathrm{mg} / \mathrm{kg} / \mathrm{bw}$ by gastric gavages route in a volume of $1 \mathrm{ml}$ during 2 months daily [17].

2.7. Measurement of Body Weights and Relative Organ Weights. Body weight was measured weekly during 2 months of each group and relative liver weight after sacrifice in the experiment period regularly.

2.8. Biochemical Analysis. The animal was sacrificed by decapitation and the trunk blood was collected. The serum of each rat was obtained by centrifugation $(3000 * \mathrm{~g}, 15$ min, $4^{\circ} \mathrm{C}$ ) and stored at $-20^{\circ} \mathrm{C}$ until biochemical analysis. The analyses of serum lipase and lipid profile (Triglycerides (TG), total cholesterol (T-Ch), and high-density lipoprotein cholesterol (HDL-C)) using the corresponding commercial kits (Biolabs, France) on an automatic biochemistry analyzer at the biochemical laboratory of $\mathrm{CHU}$ Habib Bourguiba Hospital of Sfax.

Low-density lipoprotein cholesterol concentration (LDLc) was determined by Friedewald et al. formula [18].

Serum levels of aspartate aminotransferase (AST), alanine aminotransferase (ALT), alkaline phosphatase (ALP), and lactate dehydrogenase (LDH) were measured in frozen aliquots of serum by standardized enzymatic procedures using commercial kits from (Biolabs, France) on an automatic biochemistry analyzer at the biochemical laboratory of CHU, Habib Bourguiba Hospital of Sfax. For the ornithine carbamoyltransferase (OCT) activity was determined by the colorimetric spectrophotometric methods [19].

2.9. Determination of Hematological Parameters. Hematological parameters including red blood cells (RBC), hemoglobin $(\mathrm{Hb})$, mean corpuscular volume (MCV), mean corpuscular hemoglobin $(\mathrm{MCH})$, mean corpuscular hemoglobin concentration (MCHC), white blood cell (WBC), and platelets were measured by Horiba ABX 80 Diagnostics (ABX pentra Montpellier, France).

2.10. Determination of Liver Oxidative Stress Markers. Oxidative stress was estimated through the following parameters: the extent of lipid peroxidation by measuring the thiobarbituric acid reactive substances (TBARS) in terms of malondialdehyde (MDA) formation according to Draper and Hadley [20] and expressed as nmol MDA/mg protein and the protein oxidation by measuring the advanced oxidation protein (AOPP) by Kayali et al. [21] method and expressed as $\mathrm{nmol} / \mathrm{mg}$ protein.

2.11. Determination of Non- Enzymatic and Enzymatic Antioxidants Systems. Superoxide dismutase (SOD) activity was measured by Beyer and Fridovich [22] method and expressed as $\mathrm{U} / \mathrm{mg}$ protein. Glutathione (GPx) activity was determined by the method described by Pagila and Valentine [23] and expressed as mmoles GSS/(min_mg protein). Reduced glutathione (GSH) activity was estimated according to the described method by Carlberg and Mannervik [24] and

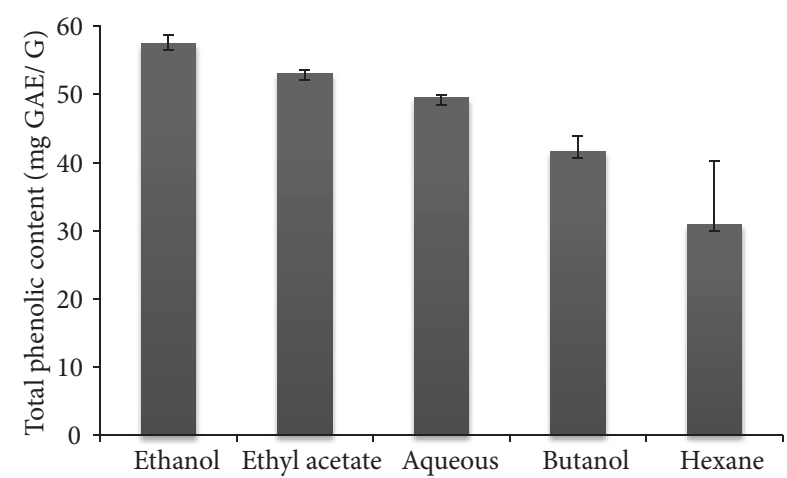

FIgURE 1: Total phenolic content of various extracts from leaves of Cynara scolymus. Values are given as means \pm SD $(n=3)$.

expressed as ug GSH/mg protein. The protein level was evaluated by Lowry et al. [25] using bovine serum albumin as the standard at $660 \mathrm{~nm}$.

2.12. Determination of ROS Production. According to Gupta et al. [26] methods, the reactive oxygen species formation (ROS) in liver tissue was described with some modifications. Liver samples $(200 \mathrm{mg})$ were homogenized in ice-cold Tris$\mathrm{HCl}$ buffer $(40 \mathrm{mM}, \mathrm{pH} 7.4)(1: 10 \mathrm{w} / \mathrm{v})$. Then, $100 \mathrm{~mL}$ of samples of tissue homogenate were mixed with Tris- $\mathrm{HCl}$ buffer $(1 \mathrm{~mL})$ and $5 \mathrm{~mL}$ of 20,70-dichlorofluorescein diacetate (10 mM) (Sigma-Aldrich, St. Louis, MO). The mixture then was incubated for $30 \mathrm{~min}$ in $37^{\circ} \mathrm{C}$. After the incubation, the fluorescence intensity of the samples was assessed using a FLUOstar Omega multifunctional microplate reader $\left(\lambda_{\text {excitation }} 485 \mathrm{~nm}\right.$ and $\left.\lambda_{\text {excitation }} 535 \mathrm{~nm}\right)$.

2.13. Histopathological Liver Analysis. After the sacrifice of experimental rats, a small portion of each liver tissue of each rat was eliminated and fixed in 10\% formaldehyde solution. Each washed tissues was dehydrated in increasing gradient of ethanol and finally cleared into toluene. The liver tissues were then embedded in molten paraffin wax. Sections were cut at $5 \mathrm{~mm}$ thickness and stained with hematoxylin and eosin (H\&E).

\section{Statistical Analysis}

Data are expressed as mean \pm standard deviation (mean \pm $\mathrm{SD}$ ). The one-way analysis of variance (ANOVA) and the Tukey post hoc test were performed on the data for intergroup comparisons. Database management and statistical analysis were performed using SPSS (SPSS Inc., Chicago, IL) statistical software package. The nominal statistical significance level was set at 0.05 .

\section{Results}

4.1. Determination of Total Phenol Content. Figure 1 showed the highest content of total phenol content was obtained using $75 \%$ of ethanol extract from leaves of C. scolymus as 


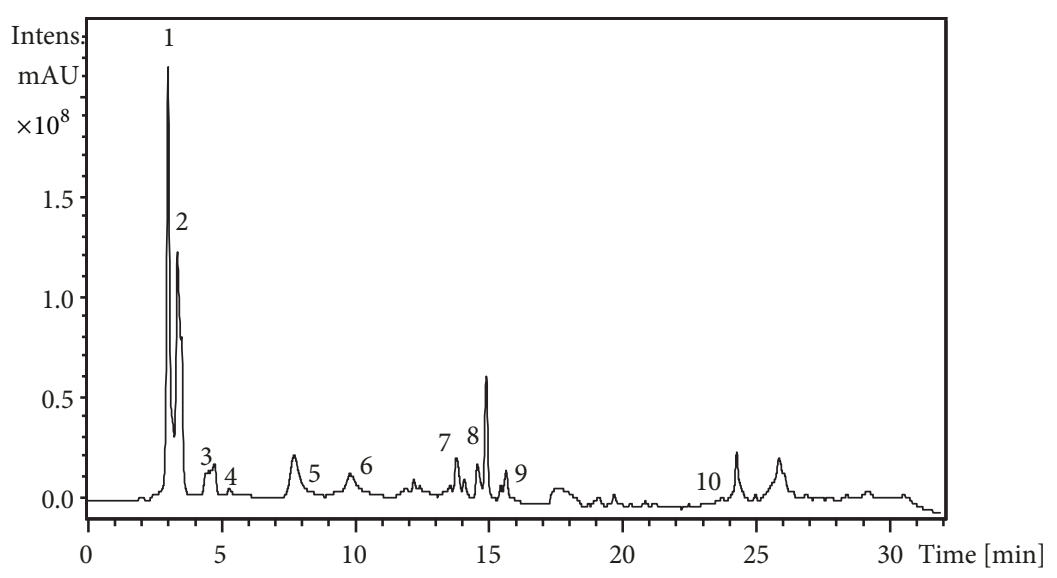

FIGURE 2: LC-MS/MS chromatogram of ethanol extract from leaves of Cynara scolymus at two different wavelengths (200 and $700 \mathrm{~nm})$.

the extraction solvent and corresponded to $54.54 \pm 1.26 \mathrm{mg}$ GAE/g dry extract, followed by ethyl acetate, aqueous, and butanol extracts, while the hexane extract was the lowest in the total phenol content (30.91 $\pm 9.36 \mathrm{mg} \mathrm{GAE} / \mathrm{g}$ dry extract).

4.2. LC-MS/MS Analysis. From the HPLC chromatogram of the EEA from leaves of Cynara scolymus, ten phenolic components were identified (Figure 2). Table 1 showed the retention times, UV max, the mode (+ or -) as well as the base peak (MS), and fragment ion (MS2). In the analysis of peak 1 by LC-MS/MS, a positive molecular ion at $[\mathrm{MS}+\mathrm{H}]+$ at $\mathrm{m} / \mathrm{z} 122.4$ as well as a fragment ion at $\mathrm{m} / \mathrm{z}$ of 122.3 , corresponding to salicylic acid-o-hexoside, was observed. Peak 2 exhibited from the same analysis a negative molecular ion $[\mathrm{MS}-\mathrm{H}]-$ at $\mathrm{m} / \mathrm{z} 117.2$ as well as a fragment ion at an $\mathrm{m} / \mathrm{z} 100$, corresponding to chlorogenic acid. Peak 3 had a negative molecular ion [MS-H]- at $\mathrm{m} / \mathrm{z}$ of 112 and three negative fragment ions at $\mathrm{m} / \mathrm{z}$ of $214.8,178.8$, and 352.8 corresponding to a 3-mono-o-caffeoylquinic acid. Peak 4 exhibited a negative molecular ion at $[\mathrm{MS}-\mathrm{H}]-$ at $\mathrm{m} / \mathrm{z} 141$ and the negative fragment ion at $\mathrm{m} / \mathrm{z}$ of 265.9 which correspond to apigenin-7-glucoside. Peak 6 revealed a negative molecular ion [MS-H]- at $\mathrm{m} / \mathrm{z} 275$ and three negative fragment ions at $\mathrm{m} / \mathrm{z}$ of $529.7,350.8$, and 284.7 . The corresponding compound was identified as luteolin-7-o-rutinoside. Compounds in peak 7 had a negative molecular ion at $\mathrm{m} / \mathrm{z} 327.1$ and fragment at $\mathrm{m} / \mathrm{z}$ of 170.9; this is suggestive of a dihydroxypropiophendhexoside compound. The kaempferol 3-o-rutinoside was identified in peak 8 with a negative molecular ion at [MS-H]at $\mathrm{m} / \mathrm{z}$ of 395 and fragmentation products at $\mathrm{m} / \mathrm{z}$ of 529.7 , 288.9, and 307. Peak 9 revealed a negative molecular ion at [MS-H]- at $\mathrm{m} / \mathrm{z}$ of 431 and three negative fragment ions at $\mathrm{m} / \mathrm{z}$ of 434.7, 294.9, and 344.8; the corresponding compound was identified as quercetin-o-pentoside. Compounds in peak 10 had a negative molecular ion at $\mathrm{m} / \mathrm{z} 623$ and fragment at $\mathrm{m} / \mathrm{z}$ of 255.1; this is suggestive as Caffeic acid compound. In the analysis of compound in peak 5 with referring to standards and literature, it was not well identified.

4.3. Lipase Pancreatic Inhibition Activity. Table 2 showed that EEA presented a great pancreatic lipase inhibition with an
IC50 value of $61.50 \mu \mathrm{g} / \mathrm{mL}$ as compared to Orlistat specific inhibitor $(\mathrm{IC} 50=17.76 \mu \mathrm{g} / \mathrm{mL})$. The potential in in vitro inhibitory effect of lipase was observed to EEA compared to the other extracts that leads us to apply it for in vivo investigation.

4.4. Evaluation of Body Absolute and Relative Organ Weights. HFD groups showed a significant increase in body weight and liver relative weight $(\mathrm{p}<0.001)$ compared with the control groups, while HFD groups treated with EEA at doses (200$400 \mathrm{mg} / \mathrm{kg} / \mathrm{bw})$ observed a significant decrease $(\mathrm{p}<0.001)$ when compared to HFD groups (Table 3, Figure 3).

4.5. Effect of a High Fat Diet on Lipase Pancreatic in Serum. Our results indicated that treatment with HFD for 8 months showed a significantly elevated $(\mathrm{p}<0.001)$ in lipase pancreatic activity in serum by $75 \%$ in compared with control groups, while the treatment with EEA from leaves of C. scolymus and ATOR decreased significantly $(\mathrm{p}<0.001)$ these levels by $56 \%$ in serum compared with HFD groups (Figure 4).

4.6. Effect of a High Fat Diet on Serum Lipid Profile. The effect of HFD on serum biochemical was shown in Table 4. The levels of TG, TC, and LDL-c showed a significant $(\mathrm{p}<0.001)$ increase by $46.06 \%, 69.36 \%$, and $66.66 \%$ as compared to control groups. Meanwhile, the serum level of HDL-c significantly $(\mathrm{p}<0.001)$ decreased by $59 \%$ in HFD groups.

The administration of EEA (200-400 $\mathrm{mg} / \mathrm{kg} / \mathrm{bw})$ restored normal levels of TC by $45.67 \%, 67.78 \%$, and $36.22 \%$, TG by $54.92 \%, 68.08 \%$, and $60.11 \%$, and LDL-c by $27.27 \%, 33.33$ $\%$, and $44.44 \%(\mathrm{p}<0.001)$ and caused significant increase in serum HDL-c level by $44.27 \%, 60.79 \%$, and $38.76 \%$ $(\mathrm{p}<0.001)$ compared to HFD groups.

Our results indicated that HFD for a duration of 8 months has significantly increased the risk of atherosclerosis indicated by the atherogenic index of plasma (AIP) and Castelli's risk index-I (CRI-I). However the therapy with EEA $(200-400 \mathrm{mg} / \mathrm{kg} / \mathrm{bw})$ significantly $(\mathrm{p}<0.001)$ decreased the AIP and (CRI-I) levels compared to HFD groups. 
TABLE 1: Identification of phenolic compounds in ethanol extract from leaves of C. scolymus using their retention times, LC/MS, and LC-MS/MS data.

\begin{tabular}{lcccccc}
\hline Peak $^{\mathrm{a}}$ & RT $(\mathrm{min})$ & $\mathrm{m} / \mathrm{z}$ & Mode $(+/-)$ & $\lambda_{\max }(\mathrm{min})$ & MS/MS & Tentative ID \\
\hline 1 & 3.00 & 122.3 & + & $200-700$ & 82 & Salicylic acid-o-hexoside \\
2 & 3.7 & 117.2 & - & $200-700$ & 100 & Chlorogenic acid \\
3 & 4.2 & 112 & - & $200-700$ & $214.8,178.8,352.8$ & 3-mono-o-cafeoylquinic acid \\
4 & 5.3 & 141 & - & $200-700$ & 265.9 & Apigenin-7-glucoside \\
5 & 8.4 & 223 & - & $200-700$ & 331.4 & Unknown \\
6 & 10.30 & 275 & - & $200-700$ & $529.7,350.8,284.7$ & Luteolin-7-o-rutinoside \\
7 & 13.5 & 327.1 & - & $200-700$ & 170.9 & Dihydroxypropiophend-hexoside \\
8 & 14.8 & 395 & - & $200-700$ & $529.7,288.9,307$ & Kampferol 3-o-rutinoside \\
9 & 16.2 & 431 & - & $200-700$ & $434.7,294.9,344.8$ & Quercetin-o-pentoside \\
10 & 23.3 & 623 & - & $200-700$ & 255.1 & Caffeic acid \\
\hline
\end{tabular}

Identification was aided by comparison with reference standards that were available and by correlation with previous literature reports.

${ }^{a}$ Peak numbers and retention times (Rt) refer to LC/MS chromatograms in Figure 2.

TABLE 2: The inhibitory capacity of C. scolymus leaves extracts against lipase pancreatic activity.

\begin{tabular}{|c|c|c|c|}
\hline & Concentration (ug/ml) & $\%$ Inhibition & CI50 (ug/ml) \\
\hline \multirow{3}{*}{ Orlistat } & 25 & $80.25 \pm 1.08$ & \multirow{3}{*}{17.76} \\
\hline & 50 & $97.21 \pm 0.59$ & \\
\hline & 100 & $90.35 \pm 1.20$ & \\
\hline \multirow{3}{*}{ Hexane } & 25 & $17.46 \pm 0.05$ & \multirow{3}{*}{200.15} \\
\hline & 50 & $20.13 \pm 1.19$ & \\
\hline & 100 & $49.81 \pm 0.28$ & \\
\hline \multirow{3}{*}{ Ethylacetate } & 25 & & \multirow{3}{*}{-} \\
\hline & 50 & - & \\
\hline & 100 & & \\
\hline \multirow{3}{*}{ Butanol } & 25 & $23.09 \pm 1.88$ & \multirow{3}{*}{101.50} \\
\hline & 50 & $30.13 \pm 1.02$ & \\
\hline & 100 & $70.18 \pm 0.07$ & \\
\hline \multirow{3}{*}{ Ethanol } & 25 & $60.38 \pm 1.58$ & \multirow{3}{*}{61.50} \\
\hline & 50 & $69.23 \pm 0.84$ & \\
\hline & 100 & $73.90 \pm 1.77$ & \\
\hline \multirow{3}{*}{ Aqueous } & 25 & $36.81 \pm 0.07$ & \multirow{3}{*}{95.78} \\
\hline & 50 & $62.10 \pm 1.02$ & \\
\hline & 100 & $67.24 \pm 0.13$ & \\
\hline
\end{tabular}

All data are expressed as mean \pm SD. (-): inactive.

4.7. Effect of Cynara scolymus Leaves Extract in Hepatic Dysfunction Enzymes. HFD caused severe hepatotoxicity as evidenced by a significant elevation $(\mathrm{p}<0.001)$ of serum AST, ALT, LDH, ALP, and OCT levels, compared to control groups. However, the coadministration of EEA $(200-400 \mathrm{mg} / \mathrm{kg} / \mathrm{bw})$ and ATOR completely recovered the impaired liver functions by decreasing hepatic parameters compared with HFD groups (Table 5).

4.8. Effect of Cynara scolymus Leaves Extract on Hematological Parameters. The results indicated that, compared to control groups, there was a significant decrease in the levels of $\mathrm{RBC}, \mathrm{Hb}, \mathrm{MCV}, \mathrm{MCH}, \mathrm{MCHC}, \mathrm{WBC}$, and platelets observed in HFD groups. However, these hematological markers were considerably increased to near normal values after the treatment with EEA from leaves of C. scolymus
$(200-400 \mathrm{mg} / \mathrm{kg} / \mathrm{bw})(\mathrm{p}<0.001)$ compared with HFD groups (Table 6).

4.9. Effect of Cynara scolymus Leaves Extract in Oxidative Stress Status. HFD has significantly $(\mathrm{p}<0.001)$ increased TBARS levels by $52.29 \%$, AOPP levels by $55.58 \%$, and liver ROS intracellular production by $53.33 \%$ as compared with HFD groups (Table 7). After all, treatment with EEA at both doses $(200-400 \mathrm{mg} / \mathrm{kg} / \mathrm{bw})$ in HFD rats has improved the antioxidant capacities significantly $(\mathrm{p}<0.001)$ in the liver by increasing SOD, GP-x, and GSH activities as compared to HFD groups.

4.10. Histopathological Analysis of Liver. To approve our results on the biochemical analysis, we examined the pathologic changes in liver microscopically. Our study revealed that 
TABLE 3: Effect of treatment with C. scolymus leaves extract on body weight.

\begin{tabular}{lccccc}
\hline Groups & Cont & HFD & HFD+EEA $(200 \mathrm{mg} / \mathrm{kg} / \mathrm{bw})$ & HFD+EEA $(400 \mathrm{mg} / \mathrm{kg} / \mathrm{bw})$ & HFD+ATOR \\
\hline Day 0 & $210.00 \pm 0.67$ & $265.66 \pm 3.45 * * *$ & $260.45 \pm 2.21$ & $266.00 \pm 2.13$ & $255.78 \pm 2.30 * *$ \\
Day 65 & $214.50 \pm 10.40$ & $280.10 \pm 13.93 * * *$ & $222.5 \pm 15.00^{\# \#}$ & $234.33 \pm 10.11^{\# \# \#}$ & $216.66 \pm 18.00^{\# \# \#}$ \\
\hline
\end{tabular}

HFD groups were orally administered with ethanol extract (EEA) from leaves of C. scolymus and atorvastatin (ATOR) at the doses mentioned earlier for 60 days. Values are given as means $\pm \mathrm{SD}(\mathrm{n}=6) . * * \mathrm{p} \leq 0.01$ and $* * * \mathrm{p} \leq 0.001$ were considered significant compared to control groups; ${ }^{\# \# \#} \mathrm{p} \leq 0.001$ was considered significant compared to HFD groups; ${ }^{\ddagger} \mathrm{p} \leq 0.05$ was considered significant compared to HFD groups treated with ATOR.

TABLE 4: Effect of treatment with C. scolymus leaves extract on serum lipid profile.

\begin{tabular}{lccccc}
\hline Groups & Cont & HFD & $\begin{array}{c}\text { HFD + EEA } \\
(200 \mathrm{mg} / \mathrm{kg} / \mathrm{bw})\end{array}$ & $\begin{array}{c}\text { HFD+EEA } \\
(400 \mathrm{mg} / \mathrm{kg} / \mathrm{bw})\end{array}$ & HFD+ATOR \\
\hline TG $(\mathrm{mmol} / \mathrm{L})$ & $1.00 \pm 0.29$ & $2.50 \pm 0.40 * * *$ & $1.13 \pm 0.20^{\# \# \#}$ & $0.8 \pm 0.42^{\# \# \#}$ & $1.00 \pm 0.29^{\# \# \#}$ \\
T-Ch $(\mathrm{mmol} / \mathrm{L})$ & $1.37 \pm 0.12$ & $3.50 \pm 0.55 * * *$ & $1.60 \pm 0.15^{\# \# \#}$ & $1.70 \pm 0.15^{\# \# \#}$ & $1.62 \pm 0.08^{\# \# \#}$ \\
LDL- c (mmol/L) & $0.60 \pm 0.19$ & $1.80 \pm 0.07 * * *$ & $1.30 \pm 0.35^{\# \# \#}$ & $0.80 \pm 0.01^{\# \#}$ & $0.45 \pm 0.40^{\# \# \#}$ \\
HDL-c $(\mathrm{mmol} / \mathrm{L})$ & $1.44 \pm 0.33$ & $0.50 \pm 0.10 * * *$ & $0.80 \pm 0.33^{\# \# \#}$ & $1.19 \pm 0.07^{\# \# \#}$ & $0.76 \pm 0.08^{\# \# \#}$ \\
AIP & $0.95 \pm 0.17$ & $6.88 \pm 0.14 * * *$ & $2.00 \pm 0.12^{\# \# \#}$ & $1.48 \pm 0.19^{\# \# \# \#}$ & $2.13 \pm 0.20^{\# \# \#}$ \\
CRI-I & 0.951 & 7 & 2 & 1.42 & 2.13 \\
\hline
\end{tabular}

HFD groups were orally administered with ethanol extract (EEA) from leaves of C. scolymus and atorvastatin (ATOR) at the doses mentioned earlier for 60 days. Values are given as means $\pm \mathrm{SD}(\mathrm{n}=6) . * * * \mathrm{p} \leq 0.001$ was considered significant compared to control groups; ${ }^{\# \#} \mathrm{p} \leq 0.001$ was considered significant compared to HFD groups; ${ }^{¥} \mathrm{p} \leq 0.05$ and ${ }^{¥} \mathrm{p} \leq 0.01$ were considered significant compared to HFD groups treated with ATOR.

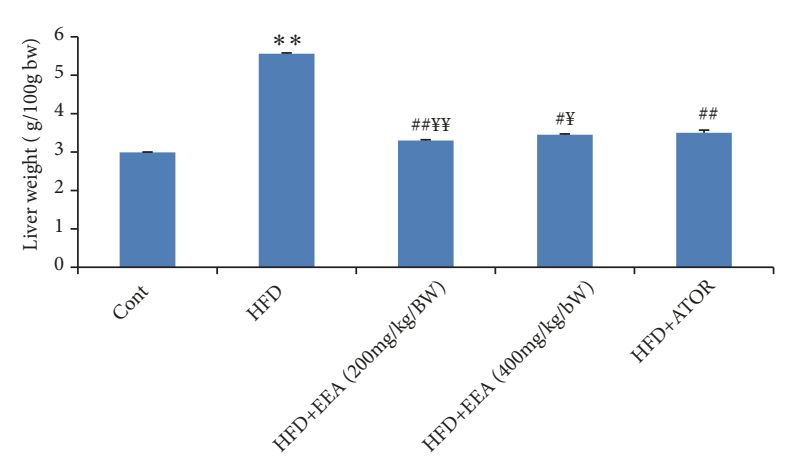

FIGURE 3: Effect of C. scolymus leaves extract on the liver weight of control and HFD groups. HFD groups were orally administered with ethanol extract (EEA) from leaves of C. scolymus and atorvastatin (ATOR) at the doses mentioned earlier for 60 days. Values are given as means $\pm \mathrm{SD}(\mathrm{n}=6)$. $* * \mathrm{p} \leq 0.01$ was considered significant compared to control groups; ${ }^{\#} \mathrm{p} \leq 0.05 ;{ }^{\# \#} \mathrm{p} \leq 0.01$ were considered significant compared to HFD groups; ${ }^{¥} \mathrm{p} \leq 0.05 ;{ }^{¥} \mathrm{p} \leq 0.01$ were considered significant compared to HFD groups treated with atorvastatin.

the histological findings in the liver indicated the presence of lipid accumulation in hepatic lobule in the case of the HFD groups, indicated by arrows (Figure 5(b)). However, the treatment with EEA from leaves of C. scolymus (200-400 $\mathrm{mg} / \mathrm{kg} / \mathrm{bw}$ ) and ATOR showed a protective effect in the form of the liver histoarchitecture (Figures 5(c), 5(d), and 5(e)).

\section{Discussion}

One of the most chronic metabolic diseases was obesity, including severe human complication. It is closely related to type 2 diabetes, hypertension and cardiovascular disease according to Wilis et al. [27], cancer, respiratory

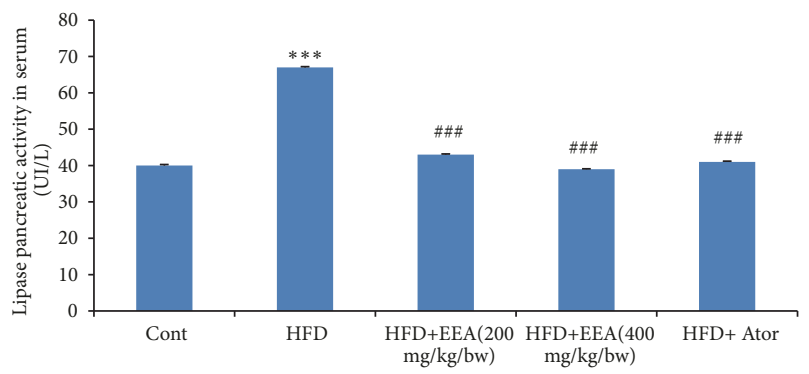

FIGURE 4: Effect of treatment with C. scolymus leaves extract on lipase activity in serum of control and HFD groups. HFD groups were orally administered with ethanol extract from leaves of $C$. scolymus and atorvastatin (ATOR) at the doses mentioned earlier for 60 days. Values are given as means \pm SD $(\mathrm{n}=6) . * * * \mathrm{p} \leq 0.001$ was considered significant compared to control groups; ${ }^{\# \# \# ~} \mathrm{p} \leq 0.001$ was considered significant compared to HFD groups.

complications, and osteoarthritis [28], which has been increased at an alarming percentage around the world.

According to Mnafgui et al. [29], the detection of antiobesity drugs without undesirable side effect has become a big problem. Nowadays, the medicinal plant has been used as a complementary treatment, in order to decrease the undesirable effect of drugs treated by patients.

This research was carried out to appreciate the potentiality effect of C. scolymus leaves extract on obese rat induced HFD and to assess its impact therapeutic about obesity.

Chakrabarti [30] demonstrated that the use of safer lipase inhibitors is considered as an efficacious therapeutic approach to overcome obesity and hyperlipidemia by the delay of the digestion and absorption of fat.

It is known that the major role of pancreatic lipase is the digestion of fats by dividing dietary triglycerides 


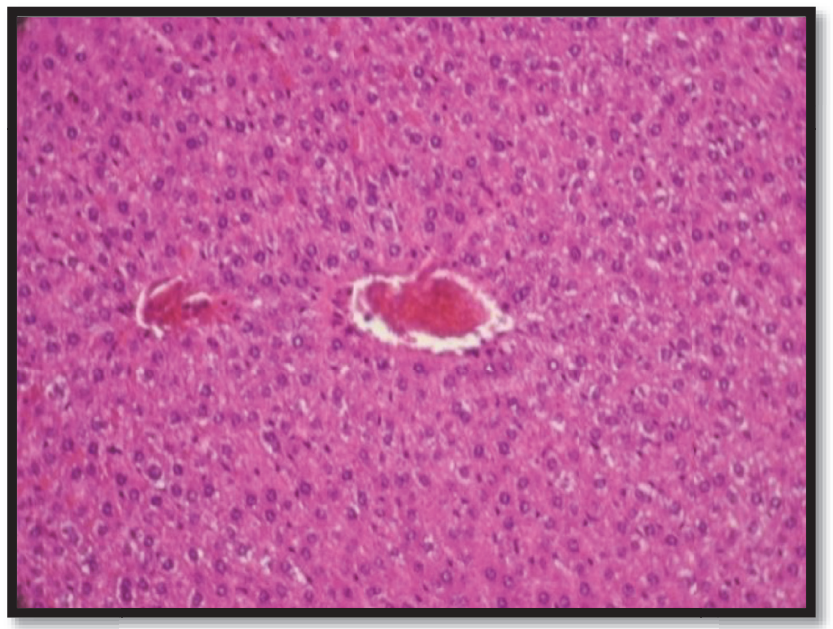

(a)

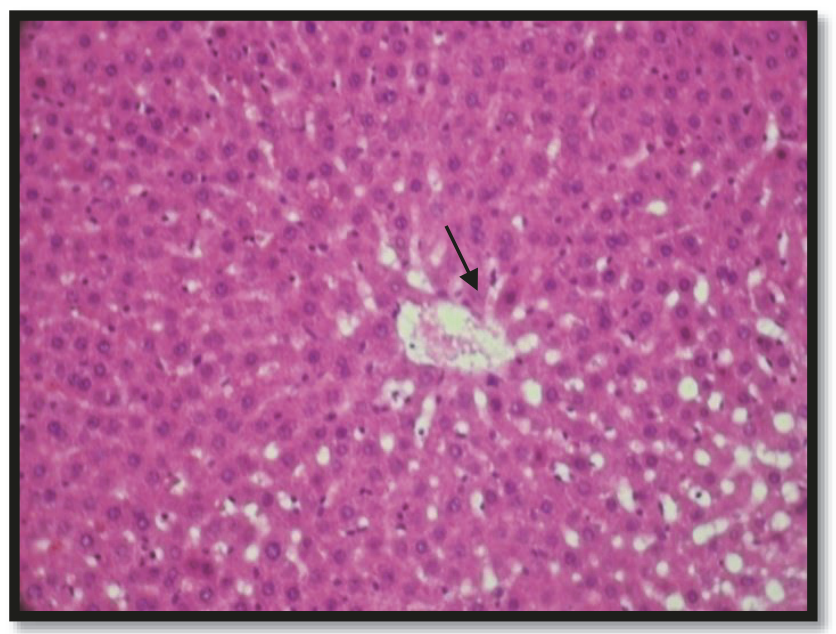

(c)

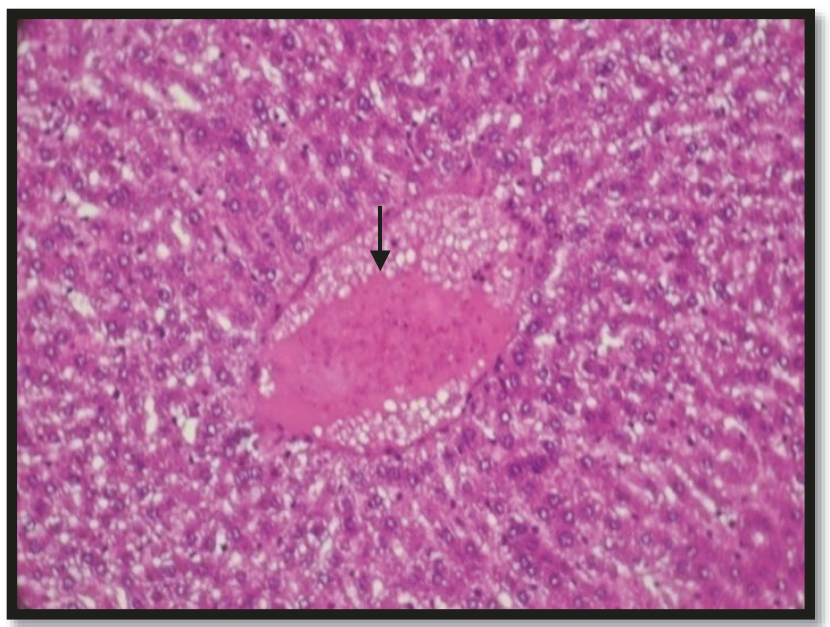

(b)

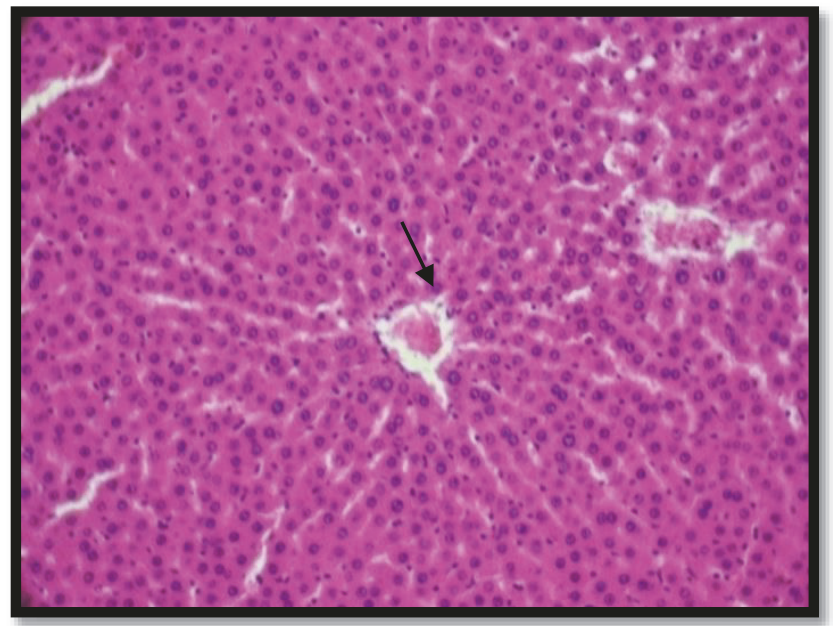

(d)

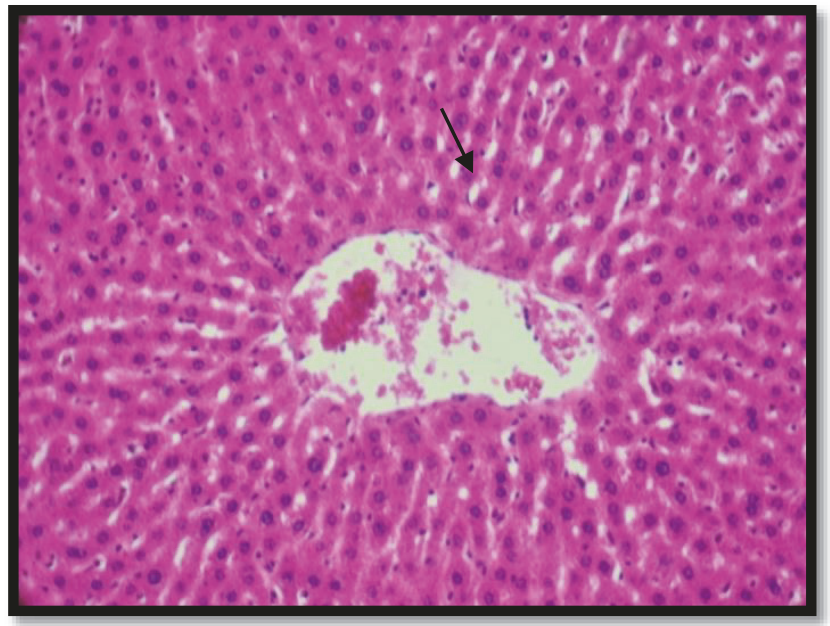

(e)

Figure 5: Histopathological examination of liver in experimental groups of rats. (a) represents a normal hepatic lobules of the control groups; (b) represents histopathological investigation of liver tissue in rats fed on HFD groups which showed severe macrovascular fatty changes distributed throughout the liver lobules; (c and d) represent HFD+ EEA (200- 400mg/kg/bw) groups, which showed a reduction in accumulation of fatty throughout the liver lobules; (e) represents HFD+ ATOR groups in which a potential protective action was shown $(\mathrm{H} \& \mathrm{E} \times 400)$. 
TABLE 5: Effect of treatment with C. scolymus leaves extract on liver dysfunction enzymes.

\begin{tabular}{lccccc}
\hline Groups & AST (UI/L) & ALT (UI/L) & LDH (UI/L) & ALP (UI/L) & OCT (mg / g protein) \\
\hline Cont & $131.9 \pm 1.50$ & $42.76 \pm 1.78$ & $76.2 \pm 2.5$ & $64.78 \pm 2.50$ & $10.5 \pm 1.3$ \\
HFD & $273.7 \pm 2.33 * * *$ & $76.03 \pm 7.31 * * *$ & $137 \pm 8.03 * * *$ & $206.66 \pm 6.52 * * *$ & $7.9 \pm 0.5 *$ \\
HFD+EEA(200mg/kg/bw) & $128.56 \pm 7.87^{\# \# \#}$ & $41.51 \pm 8.03^{\# \# \#}$ & $70.18 \pm 8.03^{\# \#}$ & $72.83 \pm 8.00^{\# \#}$ & $5.7 \pm 0.2^{\#}$ \\
HFD+EEA(400mg/kg/bw) & $112.18 \pm 5.47^{\# \# \#}$ & $36.56 \pm 1.85^{\# \# \#}$ & $63.2 \pm 1.85^{\# \# \#}$ & $72.20 \pm 3.00^{\# \#}$ & $6.0 \pm 0.1$ \\
HFD+ATOR & $169.18 \pm 4.37^{\# \# \#}$ & $49.36 \pm 3.73^{\# \# \# \# ¥}$ & $84.5 \pm 1.22^{\# \#}$ & $89.2 \pm 4.18^{\# \#}$ & $6.4 \pm 0.7$ \\
\hline
\end{tabular}

HFD groups were orally given ethanol extract (EEA) from leaves of C. scolymus and atorvastatin (ATOR) at the doses mentioned earlier for 60 days. Values are given as means $\pm \mathrm{SD}(\mathrm{n}=6) . * \mathrm{p} \leq 0.05$ and $* * * \mathrm{p} \leq 0.001$ were considered significant compared to control groups; ${ }^{\#} \mathrm{p} \leq 0.05,{ }^{\# \#} \mathrm{p} \leq 0.01$, and ${ }^{\# \#} \mathrm{p} \leq 0.001$ were considered significant compared to HFD groups; ${ }^{¥} \mathrm{p} \leq 0.05$ and ${ }^{¥ ¥} \mathrm{p} \leq 0.01$ were considered significant compared to HFD groups treated with ATOR.

TABLE 6: Effect of treatment with C. scolymus leaves extracts on hematological parameters.

\begin{tabular}{|c|c|c|c|c|c|}
\hline Groups & Cont & HFD & HFD+EEA $(200 \mathrm{mg} / \mathrm{kg} / \mathrm{bw})$ & HFD+EEA $(400 \mathrm{mg} / \mathrm{kg} / \mathrm{bw})$ & HFD+ATOR \\
\hline $\operatorname{GR}\left(\times 10^{6}\right)$ & $6.96 \pm 2.37$ & $9.13 \pm 0.09$ & $8.91 \pm 0.04^{¥ ¥}$ & $9.00 \pm 0.07^{\# ¥ ¥ ¥}$ & $8.48 \pm 0.04^{\# \# \#}$ \\
\hline $\mathrm{Hb}(\mathrm{g} / \mathrm{dL})$ & $12.55 \pm 0.91$ & $15.15 \pm 0.91 * * *$ & $14.85 \pm 0.63$ & $15.00 \pm 0.21$ & $14.80 \pm 0.14$ \\
\hline HCT(fL) & $36.25 \pm 0.96$ & $44.35 \pm 1.90 * * *$ & $43.45 \pm 1.90$ & $38.55 \pm 0.35^{\# ¥ ¥ ¥ 䒑 䶹}$ & $35.75 \pm 0.07^{\#}$ \\
\hline VGM(fL) & $50.55 \pm 0.63$ & $54.9 \pm 3.53$ & $48.75 \pm 2.61$ & $50.9 \pm 0.00$ & $50.55 \pm 0.63$ \\
\hline TCMH (g/dL) & $13.45 \pm 4.73$ & $33.7 \pm 0.15 * *$ & $16.65 \pm 0.91^{\# \#}$ & $16.75 \pm 0.07^{\# \# \# ¥ ¥ ¥}$ & $17.45 \pm 0.07^{\# \#}$ \\
\hline $\mathrm{MCHC}(\mathrm{g} / \mathrm{dL})$ & $31.6 \pm 1.97$ & $33.7 \pm 1.27$ & $30.2 \pm 0.00$ & $32.85 \pm 0.21$ & $32.85 \pm 0.21$ \\
\hline $\mathrm{GB}\left(\times 10^{3} / \mathrm{uL}\right)$ & $6.82 \pm 2.06$ & $17.45 \pm 2.04 * *$ & $10.41 \pm 2.06^{\#}$ & $11.2 \pm 1.12^{\#}$ & $9.46 \pm 1.08^{\# \#}$ \\
\hline $\operatorname{PLT}\left(\times 10^{3} / \mathrm{uL}\right)$ & $859 \pm 9.23$ & $1260 \pm 9.34 * * *$ & $839.5 \pm 8.45^{\# \#}$ & $914.5 \pm 11.87^{\# \#}$ & $879 \pm 8.21^{\# \#}$ \\
\hline
\end{tabular}

HFD groups were orally administered with ethanol extract (EEA) from leaves of C. scolymus and atorvastatin (ATOR) at the doses mentioned earlier for 60 days. Values are given as means $\pm \mathrm{SD}(\mathrm{n}=6) . * * \mathrm{p} \leq 0.01$ and $* * * \mathrm{p} \leq 0.001$ were considered significant compared to control groups; ${ }^{\#} \mathrm{p} \leq 0.05,{ }^{\# \#} \mathrm{p} \leq 0.01$, and ${ }^{\# \# \# ~} \mathrm{p} \leq 0.001$ were considered significant compared to HFD groups; ${ }^{¥ ¥} \mathrm{p} \leq 0.01$ and ${ }^{¥ ¥ ¥} \mathrm{p} \leq 0.001$ were considered significant compared to HFD groups treated with ATOR.

into monoacylglycerides and free fatty acids and then is the absorption by enterocytes. Among the drugs used for the prevention of obesity and hyperlipidemia by inhibition of the pancreatic lipase activity by the Orlistat [31], from our results, the pancreatic lipase activity was inhibited by EEA by hydrolyzing of dietary triglycerides nonabsorbable into monoglycerides and free fatty acids absorbable by the intestine. Our results were consistent with the observation by Mnafgui et al. [29]. Accordingly, we can explore the mentioned ethanol extract in vivo. The inhibition of pancreatic lipase activity was one of the solutions to avoid obesity complication [32]. The present research evidenced that EEA inhibited lipase activity in the plasma in HFD groups, which make a decrease in serum T-Ch, LDL-c, and TG levels as well as a significant reduction in the calculated atherogenic index (AI). Consequently, it showed an increase in HDL-c and a decrease in body and liver weight like antiobesity action [33]. These results were confirmed by histological findings which proved a fatty disposition throughout the liver lobules. So it is clear that the administration of EEA from leaves of $C$. scolymus for two months caused a suppressive effect on fat accumulation in all experimental groups.

These results were confirmed to Abdel Magied et al. [34] who showed the strongest hypotriglyceridemic and hypocholesterolemic effects of C. scolymus leaves extract from Egypt; moreover, this study showed the hypocholesterolemic effect of aqueous extract from leaves of C. scolymus at doses $(150,300$, and $600 \mathrm{mg} / \mathrm{kg} \mathrm{bw})$ for one month of treatment, similar to that reported by Küskü-Kiraz et al. [35] who revealed a significant decrease in Ch-T and TG level in $C$. scolymus leaves extract at doses of $1,5 \mathrm{mg} / \mathrm{kg}$ bw for two weeks in hypercholesterolemic diet rats. Meanwhile, any reduction was observed in LDL- c, TG, and VLDL-c level with a hydroalcoholic extract from leaves of C. scolymus at doses of $100-400 \mathrm{mg} / \mathrm{kg} / \mathrm{bw}$ for two weeks of treatment.

The efficacious hypolipidemia effect of EEA might be associated with a high content of active compounds richness Cynara leaves such as phenols, flavonoids, and tannins. Among these active constituents identified by LC-MS/MS, it was mentioned that cynarin and luteolin play a crucial role in inhibiting cholesterol and triglycerides synthesis according to Ben Salem et al. [36]. Some studies showed that luteolin compound could inhibit $60 \%$ of cholesterol synthesis in the digestive tract, by regulation of HMG-CoA reductase activity $[9,37]$. Moreover, Qiang et al. [38] mentioned that C. scolymus leaves extract is able to diminish hypercholesterolemia by increasing the fecal excretion of bile acids and by inhibition of HMG-CoA reductase activity, following a significant LDLc decreasing effect [39].

Our results were in accordance with the results of Kucukgergin et al. [40] who reported that Cynara leaves extract treatment for hypercholesterolemic rats was useful for decreasing serum cholesterol and triglycerides levels of rats. On the other hand, Cynara extract has been proposed to be antiatherogenic, due to its lipid-reducing and antioxidant effect [41, 42].

According to Gebhardt [8], it was reported the hepatoprotective effect of Cynara extract by reducing the cholesterol biosynthesis and the oxidation of LDL [41, 43, 44]. Among the biological activities of C. scolymus, the antimicrobial 


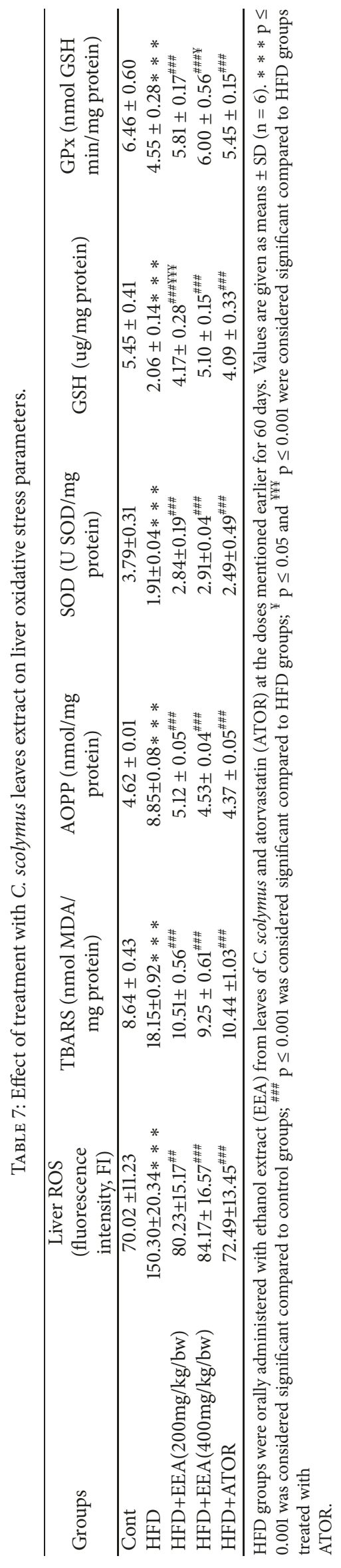


properties in the gut disorder the intestinal microflora; this allows affecting the absorption of cholesterol [45]. Moreover, Brown and Rice-Evans [46] state that chlorogenic acid and luteolin may prevent atherosclerosis disease by inhibiting LDL oxidation.

The results of the biochemical analysis were confirmed by histopathological of liver tissue which showed that EEA at doses $200 \mathrm{mg} / \mathrm{kg}$ bw $-400 \mathrm{mg} / \mathrm{kg}$ bw from leaves of $C$. scolymus treated HFD revealed a reduction in fatty infiltration in the liver. From these results, we can conclude that Cynara leaves extract may be useful for the preventive treatment of hypercholesterolemia.

Moreover, many markers proposed include mitochondrial markers, such as ornithine carbamoyl transferase, since this marker has been considered less sensitive in the detection of cellular damage than cytosolic markers such as ALT and AST [47]. However, Murayama et al. [48] showed that OCT marker was recently proved to be more sensitive than ALT and AST in the detection of hepatotoxicities induced by several toxicants. Therefore, to evaluate better the hepatotoxicity in HFD model, ALT, AST, ALP, LDH, and OCT enzymes are analyzed, and their elevation in circulation suggests significant hepatocellular damage $[49,50]$.

Our results revealed that EEA treatment significantly reduced these hepatic enzymatic; therefore the extract ameliorated the potential liver damage caused by HFD.

These results are in accordance with the results of Raida et al. [32] and Ben Abdallah et al. [51]. Many researchers showed the hepatoprotective effect of C. scolymus leaves extract, related to its active compounds. However, more researches were needed to fully explain the hepatoprotective mechanisms and cellular.

Ouchi et al. [52] state that obesity is related to an increase in inflammatory markers which characterized a lowgrade chronic inflammation. In this study, we noted that HFD provokes increase in inflammatory markers. However, the treatment with EEA (200- 400mg/kg/bw) showed a significant decrease in inflammatory markers. The antiinflammatory properties of Cynara were confirmed by Ben Salem et al. [36] in the report of nonalcoholic fatty liver disease.

Vial et al. [53] found a relationship between HFD and increased reactive oxygen species (ROS) production in the liver. ROS causes cell damage via the mechanism implying lipid peroxidation and protein oxidation that disposes tissue damage, especially in the liver [54]. In the current investigation, we found that HFD caused oxidative stress in the liver as revealed by increasing in ROS levels production as mentioned in Table 7, accompanied by increasing in lipid peroxidation and decreasing in antioxidant activities. Ohara et al. [55] reported that HFD was a set of chronic pathologies that can cause hypercholesterolemia and oxidative stress.

Among the antioxidants systems, antioxidant enzymes such as GSH, SOD, and GPx present great defense mechanisms, which play a pivotal role in maintaining the ROS under adequate concentrations. In the current study, EEA (200-400 mg/kg/bw) treatment provokes an increase of GSH, SOD, and GPx activities. As similar results found in Dianita et al. [16] and Abdel Majid et al. [34] studies, it has also been reported that Cynara leaves extract treatment caused significant increases in GSH-Px activities in the liver [56]. Kuçükgergin et al. [40] reported that Cynara leaves extract caused significant decreases in MDA levels in the liver tissues with an increase in hepatic GSH-Px activities in hypercholesterolemic rats. Moreover, Ben Salem et al. [11] proved the antioxidative effect of EEA (200-400 mg/kg bw) in the liver tissues of the diabetic rat.

The report of Mehmetcik et al. [56] showed a decrease in hepatic MDA and conjugated dienes levels and an increase in GSH and GSH-Px activities after treatment with Cynara leaves extract. An increase of antioxidant activity in erythrocytes was also found by Küçükgergin et al. [40], after treatment with water extract from Cynara which confirmed the antioxidant properties of this plant.

Many in vitro studies have shown that the antioxidant potential of Cynara is dependent on radical scavenging and metal ion chelating effect of its active constituents such as cynarin, chlorogenic acid, and flavonoids $[46,57]$. Nevertheless, the in vivo efficiency has not been confirmed sufficiently. Most in vivo studies correlated to the antioxidative capacity of Cynara and the hepatoprotective effect [58].

\section{Conclusion}

Cynara scolymus leaves extracts, especially their ethanol extract, exert a potential effect on rats induced by a high fat-rich diet. The administration of antioxidant-rich Cynara extract ameliorates the undesirable effect of a high fat diet on lipid accumulation and hepatic disorders.

\section{Data Availability}

The data used to support the findings of this study are available from the corresponding author upon request.

\section{Conflicts of Interest}

The authors declare that they have no conflicts of interest.

\section{Acknowledgments}

This research was supported by the Tunisian Ministry of Higher Education and Scientific Research.

\section{References}

[1] K. Fujioka, "Management of obesity as a chronic disease: Nonpharmacologic, pharmacologic, and surgical options," Obesity Research, vol. 10, pp. 116-123, 2002.

[2] N. Kubota, Y. Terauchi, H. Miki, H. Tamemoto, T. Yamauchi, K. Komeda et al., "PPAR gamma mediates high-fat diet-induce adipocyte hypertrophy and insulin resistance," Molecular Cell, vol. 4, 1999.

[3] W. L. Holland, J. T. Brozinick, L. P. Wang et al., "Inhibition of ceramide synthesis ameliorates glucocorticoid-, saturated-fat-, and obesity-induced insulin resistance," Cell Metabolism, vol. 5, no. 3, pp. 167-179, 2007.

[4] E. J. Park, J. H. Lee, G.-Y. Yu et al., "Dietary and genetic obesity promote liver inflammation and tumorigenesis by enhancing IL-6 and TNF expression," Cell, vol. 140, no. 2, pp. 197-208, 2010. 
[5] Y. J. Kim, Y. C. Bae, K. T. Suh, and J. S. Jung, "Quercetin, a flavonoid, inhibits proliferation and increases osteogenic differentiation in human adipose stromal cells," Biochemical Pharmacology, vol. 72, no. 10, pp. 1268-1278, 2006.

[6] S. Y. Kim, Y. J. Jin, Y. S. Choi, and T. Park, "Resveratrol exerts anti-obesity effects via mechanisms involving down-regulation of adipogenic and inflammatory processes in mice," Biochemical Pharmacology, vol. 81, no. 11, pp. 1343-1351, 2011.

[7] V. Lattanzio, P. A. Kroon, V. Linsalata, and A. Cardinali, "Globe artichoke: A functional food and source of nutraceutical ingredients," Journal of Functional Foods, vol. 1, no. 2, pp. 131144, 2009.

[8] R. Gebhardt, "Antioxidative and protective properties of extracts from leaves of the artichoke (Cynara scolymus L.) against hydroperoxide-induced oxidative stress in cultured rat hepatocytes," Toxicology and Applied Pharmacology, vol. 144, no. 2, pp. 279-286, 1997.

[9] K. Kraft, "Artichoke leaf extract — Recent findings reflecting effects on lipid metabolism, liver and gastrointestinal tracts," Phytomedicine, vol. 4, no. 4, pp. 369-378, 1997.

[10] B. M. Bonomi, "Limpiego della farina di foglie di carciofo disidratate (Cinara scolymus L.) nell'alimentazione delle manzette e delle manze," La Rivista di Scienza dell'Alimentazione, vol. 30, pp. 361-370, 2001.

[11] M. Ben Salem, R. Ben Abdallah Kolsi, R. Dhouibi et al., "Protective effects of Cynara scolymus leaves extract on metabolic disorders and oxidative stress in alloxan-diabetic rats," BMC Complementary and Alternative Medicine, vol. 17, article no. 328, 2017.

[12] L.-X. Yu, H.-X. Yan, Q. Liu et al., "Endotoxin accumulation prevents carcinogen-induced apoptosis and promotes liver tumorigenesis in rodents," Hepatology, vol. 52, no. 4, pp. 13221333, 2010.

[13] S. Zhang, L. Zheng, D. Dong et al., "Effects of flavonoids from Rosa laevigata Michx fruit against high-fat diet-induced nonalcoholic fatty liver disease in rats," Food Chemistry, vol. 141, no. 3, pp. 2108-2116, 2013.

[14] O. A. Fawole, U. L. Opara, and K. I. Theron, "Chemical and phytochemical properties and antioxidant activities of three pomegranate cultivars grown in South Africa," Food and Bioprocess Technology, vol. 5, no. 7, pp. 2934-2940, 2012.

[15] M. Nakai, Y. Fukui, S. Asami et al., "Inhibitory effects of oolong tea polyphenols on pancreatic lipase in vitro," Journal of Agricultural and Food Chemistry, vol. 53, no. 11, pp. 4593-4598, 2005.

[16] R. Dianita, I. Jantan, J. Jalil, and A. Z. Amran, "Effects of Labisia pumila var alata extracts on the lipid profile, serum antioxidant status and abdominal aorta of high-cholesterol diet rats," Phytomedicine, vol. 23, no. 8, pp. 810-817, 2016.

[17] E. Heidarian and Y. Soofiniya, "Hypolipidemic and hypoglycemic effects of aerial part of Cynara scolymus in streptozotocin-induced diabetic rats," Journal of Medicinal Plants Research, vol. 5, no. 13, pp. 2717-2723, 2011.

[18] W. T. Friedwald, R. I. Levy, and D. S. Fredrickson, "Estimation of concentration of low-density lipoprotein cholesterol in plasma without use of the preparative ultracentrifuge," Clin Chem, vol. 18, pp. 499-502, 1972.

[19] R. Tsuchiya, H. Fujise, K. Nishizono, Y. Ashida, T. Yamada, and K. Kobayashi, "Assay of ornithine carbamoyl transferase activity: modification for application to bovine serum," Journal of Veterinary Medical Science, vol. 56, no. 1, pp. 21-26, 1994.
[20] H. H. Draper and M. Hadley, "Malondialdehyde determination as index of lipid peroxidation," Methods in Enzymology, vol. 186, pp. 421-431, 1990.

[21] R. Kayali, U. Çakatay, T. Akçay, and T. Altuğ, "Effect of alphalipoic acid supplementation on markers of protein oxidation in post-mitotic tissues of ageing rat," Cell Biochemistry \& Function, vol. 24, no. 1, pp. 79-85, 2006.

[22] W. F. Beyer Jr. and I. Fridovich, "Assaying for superoxide dismutase activity: some large consequences of minor changes in conditions," Analytical Biochemistry, vol. 161, no. 2, pp. 559566, 1987.

[23] D. E. Paglia and W. N. Valentine, "Studies on the quantitative and qualitative characterization of erythrocyte glutathione peroxidase," Journal of Laboratory and Clinical Medicine, vol. 70, pp. 158-169, 1967.

[24] I. Carlberg and B. Mannervik, "Glutathione reductase in Glutamate, Glutamine, Glutathione, and Related Compounds, of Methods in Enzymology," Enzymology, vol. 113, pp. 484-490, 1985.

[25] O. H. Lowry, N. J. Rosebrough, A. L. Farr, and R. J. Randall, "Protein measurement with the folin phenol reagent," The Journal of Biological Chemistry, vol. 193, no. 1, pp. 265-275, 1951.

[26] R. Gupta, D. K. Dubey, G. M. Kannan, and S. J. S. Flora, "Concomitant administration of Moringa oleifera seed powder in the remediation of arsenic-induced oxidative stress in mouse," Cell Biology International, vol. 31, no. 1, pp. 44-56, 2007.

[27] B. E. Wisse, F. Kim, and M. W. Schwartz, "Physiology: An integrative view of obesity," Science, vol. 318, no. 5852, pp. 928929, 2007.

[28] P. G. Kopelman, "Obesity as a medical problem," Nature, vol. 404, no. 6778, pp. 635-643, 2000.

[29] K. Mnafgui, A. Derbali, S. Sayadi, N. Gharsallah, A. Elfeki, and N. Allouche, "Anti-obesity and cardioprotective effects of cinnamic acid in high fat diet- induced obese rats," Journal of Food Science and Technology, vol. 52, no. 7, pp. 4369-4377, 2014.

[30] R. Chakrabarti, "Pharmacotherapy of obesity: Emerging drugs and targets," Expert Opinion on Therapeutic Targets, vol. 13, no. 2, pp. 195-207, 2009.

[31] F. Carrière, C. Renou, S. Ransac et al., "Inhibition of gastrointestinal lipolysis by Orlistat during digestion of test meals in healthy volunteers," American Journal of Physiology-Gastrointestinal and Liver Physiology, vol. 281, no. 1, pp. G16-G28, 2001.

[32] R. Zouari, K. Hamden, A. E. Feki et al., "Protective and curative effects of Bacillus subtilis SPB1 biosurfactant on high-fat-highfructose diet induced hyperlipidemia, hypertriglyceridemia and deterioration of liver function in rats," Biomedicine \& Pharmacotherapy, vol. 84, pp. 323-329, 2016.

[33] S. Subramaniam, R. Subramaniam, S. Rajapandian, S. Uthrapathi, V. R. Gnanamanickam, and G. P. Dubey, "Antiatherogenic activity of ethanolic fraction of Terminalia arjuna bark on hypercholeterolemic rabbits," Evidence-Based Complementary and Alternative Medicine, vol. 2011, Article ID 487916, 8 pages, 2011.

[34] M. M. Abdel Magied, H. Salah EL Din, M. Z. Sahar, and M. S. Rania, "Artichoke (Cynara scolymus L.) Leaves and Heads Extracts as Hypoglycemic and Hypocholesterolemic in Rats," Journal of Food and Nutrition Research, vol. 41, pp. 60-68, 2016.

[35] Z. Küskü-Kiraz, G. Mehmetçik, S. Dogru-Abbasoglu, and M. Uysal, "Artichoke leaf extract reduces oxidative stress and lipoprotein dyshomeostasis in rats fed on high cholesterol diet," Phytotherapy Research, vol. 24, no. 4, pp. 565-570, 2010. 
[36] M. B. Salem, H. Affes, K. Ksouda et al., "Pharmacological studies of artichoke leaf extract and their health benefits," Plant Foods for Human Nutrition, vol. 70, no. 4, pp. 441-453, 2015.

[37] R. Gebhardt, "Inhibition of cholesterol biosynthesis in HepG2 cells by artichoke extracts is reinforced by glucosidase pretreatment," Phytotherapy Research, vol. 16, no. 4, pp. 368-372, 2002.

[38] Z. Qiang, S.-O. Lee, Z. Ye, X. Wu, and S. Hendrich, "Artichoke extract lowered plasma cholesterol and increased fecal bile acids in Golden Syrian hamsters," Phytotherapy Research, vol. 26, no. 7, pp. 1048-1052, 2012.

[39] M. Hosseinzadeh, F. Shekari, M. Janmohammadi, and N. Sabaghnia, "Effect of sowing date and fliar application of salicylia acid on forage yields and quality of globe artichoke (cynara scolymus L.)," Annales, vol. 8, pp. 50-59, 2013.

[40] C. Küçükgergin, A. F. AydIn, G. Özdemirler-Erata, G. Mehmetçik, N. Koçak-Toker, and M. Uysal, "Effect of artichoke leaf extract on hepatic and cardiac oxidative stress in rats fed on high cholesterol diet," Biological Trace Element Research, vol. 135, no. 1-3, pp. 264-274, 2010.

[41] M. Wang, J. E. Simon, I. F. Aviles, K. He, Q.-Y. Zheng, and Y. Tadmor, "Analysis of antioxidative phenolic compounds in artichoke (Cynara scolymus L.)," Journal of Agricultural and Food Chemistry, vol. 51, no. 3, pp. 601-608, 2003.

[42] J. F. Joy and S. L. Haber, "Clinical uses of artichoke leaf extract," American Journal of Health-System Pharmacy, vol. 64, no. 18, pp. 1904-1909, 2007.

[43] A. Jiménez-Escrig, L. O. Dragsted, B. Daneshvar, R. Pulido, and F. Saura-Calixto, "In vitro antioxidant activities of edible artichoke (Cynara scolymus L.) and effect on biomarkers of antioxidants in rats," Journal of Agricultural and Food Chemistry, vol. 51, no. 18, pp. 5540-5545, 2003.

[44] D. Zapolska-Downar, A. Zapolski-Downar, M. Naruszewicz, A. Siennicka, B. Krasnodbska, and B. Kolodziej, "Protective properties of artichoke (Cynara scolymus) against oxidative stress induced in cultured endothelial cells and monocytes," Life Sciences, vol. 71, no. 24, pp. 2897-2908, 2002.

[45] X. Zhu, H. Zhang, and R. Lo, "Phenolic compounds from the leaf extract of artichoke (Cynara scolymus L.) and their antimicrobial activities," Journal of Agricultural and Food Chemistry, vol. 52, no. 24, pp. 7272-7278, 2004.

[46] J. E. Brown and C. A. Rice-Evans, "Luteolin-rich artichoke extract protects low density lipoprotein from oxidation in vitro," Free Radical Research, vol. 29, no. 3, pp. 247-255, 1998.

[47] H. J. Zimmerman, Y. Kodera, and M. West, "Rate of increase in plasma levels of cytoplasmic and mitochondrial enzymes in experimental carbon tetrachloride hepatotoxicity," Journal of Laboratory and Clinical Medicine, vol. 66, pp. 315-323, 1965.

[48] H. Murayama, M. Ikemoto, Y. Fukuda, and A. Nagata, "Superiority of serum type-I arginase and ornithine carbamyltransferase in the detection of toxicant-induced acute hepatic injury in rats," Clinica Chimica Acta, vol. 391, no. 1-2, pp. 31-35, 2008.

[49] A. R. Srivastava, S. Kumar, G. G. Agarwal, and P. Ranjan, "Blunt abdominal injury: Serum ALT-A marker of liver injury and a guide to assessment of its severity," Injury, vol. 38, no. 9, pp. 1069-1074, 2007.

[50] S. E. Chapman and R. A. Hostutler, "A laboratory diagnostic approach to hepatobiliary disease in small animals," Veterinary Clinics of North America - Small Animal Practice, vol. 43, no. 6, pp. 1209-1225, 2013.

[51] K. R. Ben Abdallah, A. Ben Gara, R. Chaaben, and A. El Feki, "Anti-obesity and lipid lowering effects of Cymodocea nodosa sulphated polysaccharide on high cholesterol-fed-rats," Archives of Physiology and Biochemistry, Article ID 1105266, 2015.

[52] N. Ouchi, J. L. Parker, J. J. Lugus, and K. Walsh, "Adipokines in inflammation and metabolic disease," Nature Reviews Immunology, vol. 11, no. 2, pp. 85-97, 2011.

[53] G. Vial, H. Dubouchaud, K. Couturier et al., "Effects of a highfat diet on energy metabolism and ROS production in rat liver," Journal of Hepatology, vol. 54, no. 2, pp. 348-356, 2011.

[54] L. Tian, X. Shi, L. Yu, J. Zhu, R. Ma, and X. Yang, "Chemical composition and hepatoprotective effects of polyphenol-rich extract from houttuynia cordata tea," Journal of Agricultural and Food Chemistry, vol. 60, no. 18, pp. 4641-4648, 2012.

[55] Y. Ohara, T. E. Peterson, and D. G. Harrison, "Hypercholesterolemia increases endothelial superoxide anion production," The Journal of Clinical Investigation, vol. 91, no. 6, pp. 2546-2551, 1993.

[56] G. Mehmetçik, G. Özdemirler, N. Koçak-Toker, U. Çevikbaş, and M. Uysal, "Effect of pretreatment with artichoke extract on carbon tetrachloride-induced liver injury and oxidative stress," Experimental and Toxicologic Pathology, vol. 60, no. 6, pp. 475480, 2008.

[57] F. Pérez-García, T. Adzet, and S. Cañigueral, "Activity of artichoke leaf extract on reactive oxygen species in human leukocytes," Free Radical Research, vol. 33, no. 5, pp. 661-665, 2000.

[58] G. Aktay, D. Deliorman, E. Ergun, F. Ergun, E. Yeşilada, and C. Çevik, "Hepatoprotective effects of Turkish folk remedies on experimental liver injury," Journal of Ethnopharmacology, vol. 73, no. 1-2, pp. 121-129, 2000. 

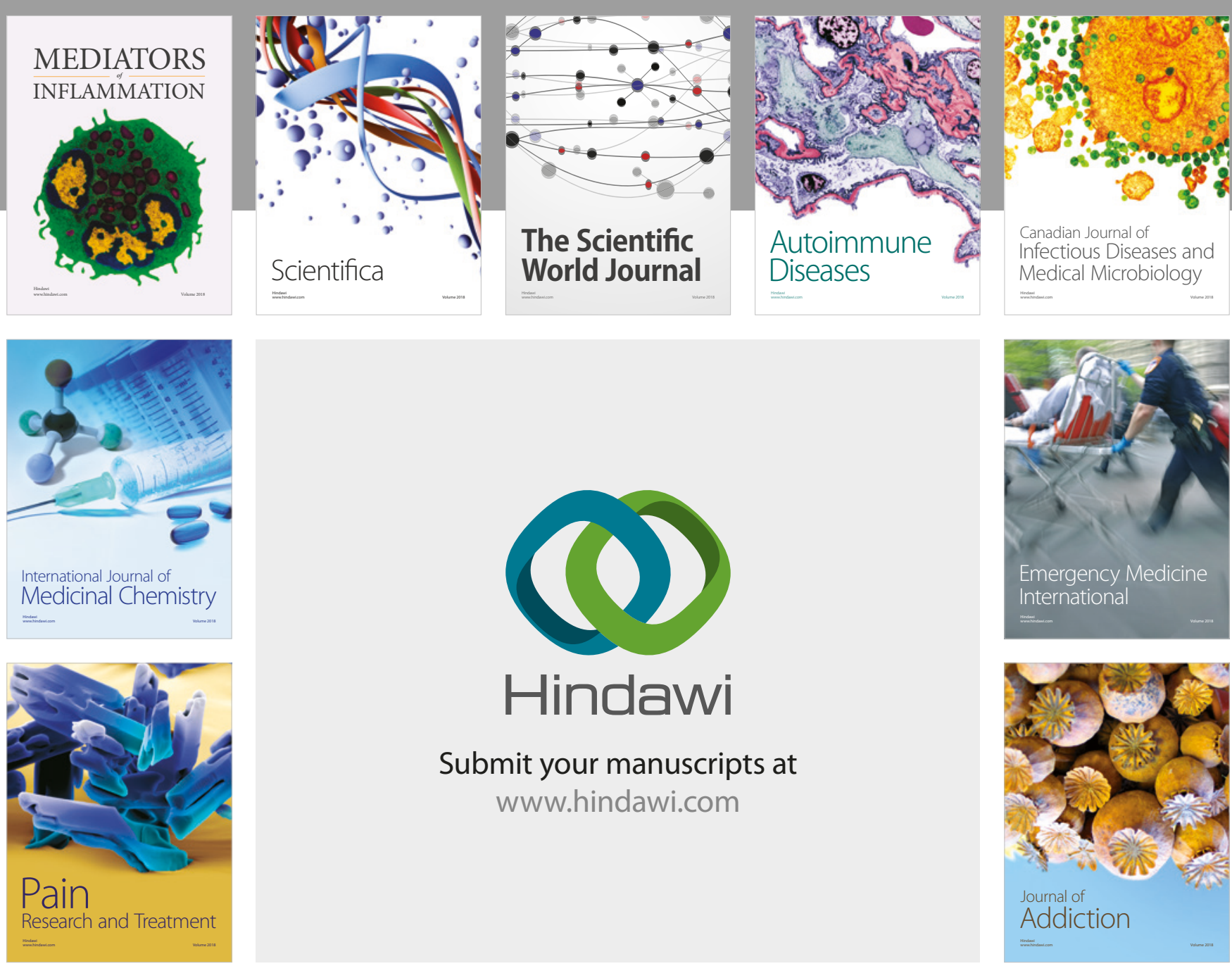

Canadian Journal of
Infectious Diseases and Medical Microbiology

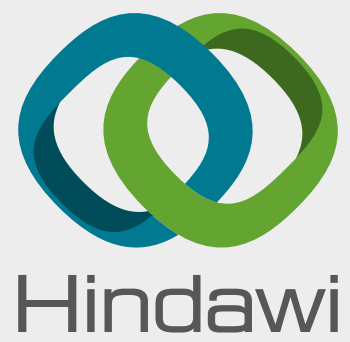

Submit your manuscripts at

www.hindawi.com
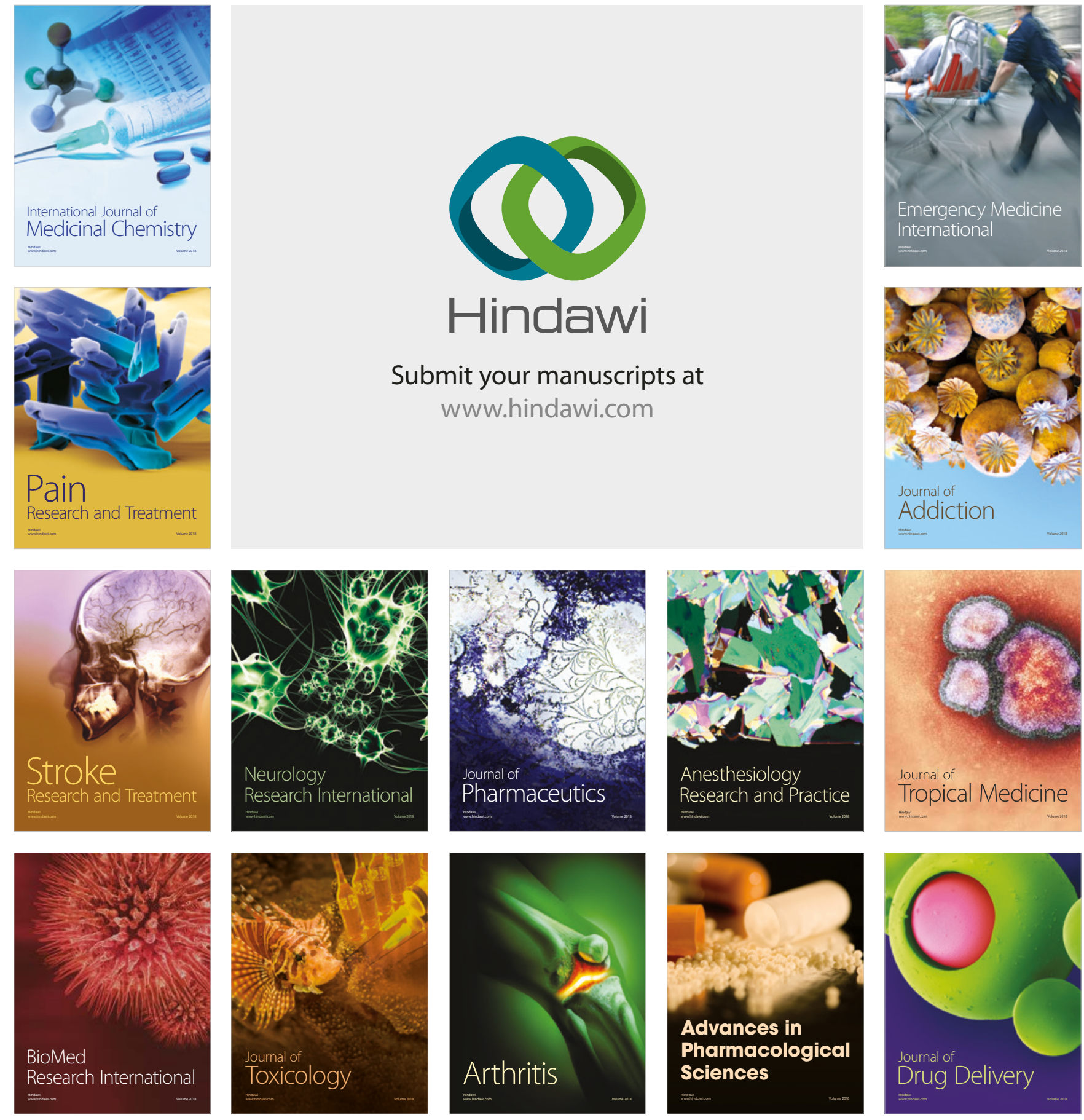